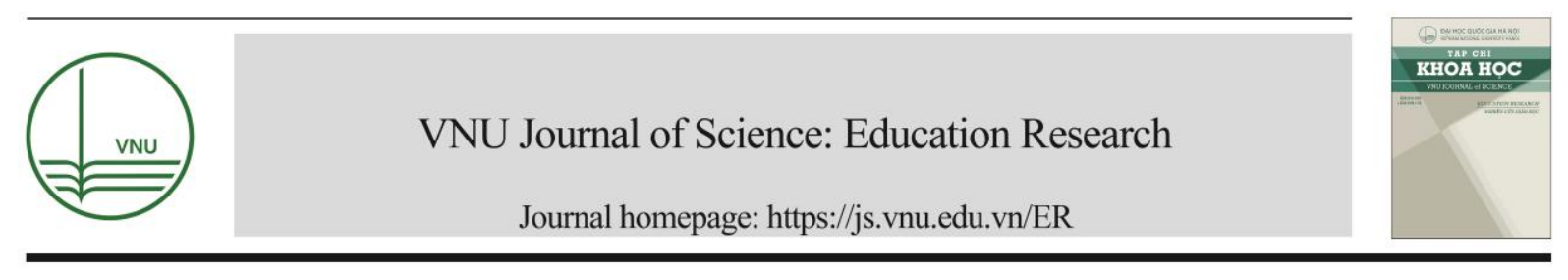

Review Article

\title{
Managing Social Work According to the Educational Philosophy of Ho Chi Minh City University of Technology and Education
}

\author{
Nguyen Thi Nhu Thuy* \\ Ho Chi Minh City University of Technology and Education, \\ Vo Van Ngan, Linh Chieu, Thu Duc, Ho Chi Minh City, Vietnam \\ Received 10 February 2020 \\ Revised 17 February 2020; Accepted 08 March 2020
}

\begin{abstract}
This article helps administrators, social workers to see the reality and difficulties in organizing, managing and implementing social activities for students at the Ho Chi Minh City University of Technical and Education - a school that does not specialize in social work, but there are diverse and diversified community-oriented activities.

Keywords: Social work, Governance, Social work Governance, Ho Chi Minh City University of Technical and Education, community, University of Technology and Education (UTE) Students.
\end{abstract}

\footnotetext{
${ }^{*}$ Corresponding author.

E-mail address: ntnthuy@ hcmute.edu.vn

https://doi.org/10.25073/2588-1159/vnuer.4368
} 


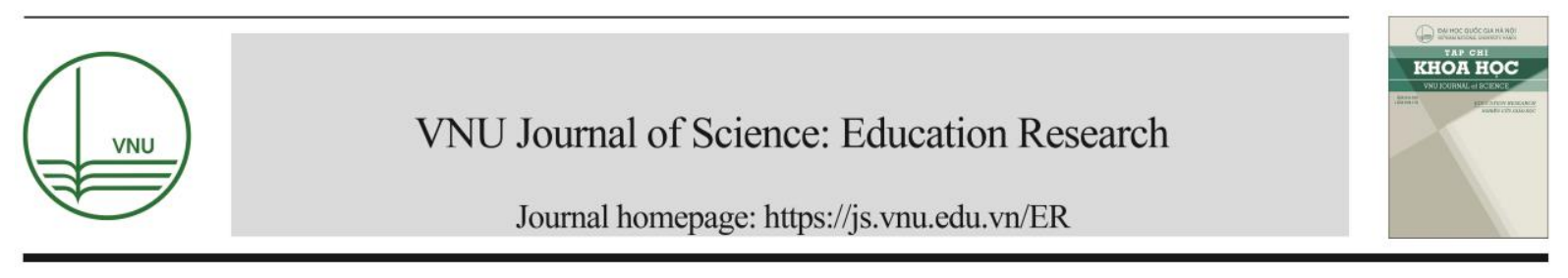

\title{
Quản trị công tác xã hội theo triết lý giáo dục của Trường Đại học Sư phạm Kỹ thuật thành phố Hồ Chí Minh
}

\author{
Nguyễn Thị Như Thúy* \\ Truờng Đại học Su phạm Kỹ thuật Thành phố Hồ Chi Minh, \\ Võ Văn Ngân, Linh Chiểu, Thủ Đức, Thành phố Hồ Chí Minh, Việt Nam \\ Nhận ngày 10 tháng 02 năm 2020 \\ Chỉnh sửa ngày 17 tháng 02 năm 2020; Chấp nhận đăng ngày 08 tháng 03 năm 2020
}

\begin{abstract}
Tóm tắt: Bài viết này giúp cho các nhà quản trị, những người làm công tác xã hội thấy được thực trạng và những khó khăn trong việc tổ chức, quản lý và triển khai các hoạt động công tác xã hội cho sinh viên tại Trường Đại học Sư phạm Kỹ thuật thành phố Hồ Chí Minh (HCMUTE) - một trường không đào tạo chuyên ngành công tác xã hội, nhưng có các hoạt động hướng đến cộng đồng khá đa dạng và phong phú.

Tù khóa: Công tác xã hội, quản trị, Quản trị công tác xã hội, Trường Đại học Sư phạm Kỹ thuật thành phố Hồ Chí Minh (HCMUTE), cộng đồng, sinh viên Trường Đại học Sư phạm Kỹ thuật.
\end{abstract}

\section{1. Đặt vấn đề}

Quản trị công tác xã hội theo triết lý giáo dục là một trong những hoạt động mà các trường đại học hiện nay đang áp dụng nhằm kết nối với mọi nguồn lực để cung cấp cho cộng đồng (cụ thể là sinh viên của các trường) những chương trình và dịch vụ hữu ích; giúp các em sinh viên có thể phát huy được năng lực của mình trong học tập, nghiên cứu và liên kết, hỗ trợ cộng đồng. Trường Đại học Sư phạm Kỹ thuật thành phố Hồ Chí Minh cũng không ngoại lệ, các hình thức và hoạt động trong công tác quản trị công tác xã hội tại Trường Đại học Sư phạm Kỹ thuật thành phố Hồ Chí Minh được cụ thể hóa bằng những hoạt động cụ thể như "Góc sẻ chia"; "Trung thu yêu thương",... là đầu

\footnotetext{
* Tác giả liên hệ.

Địa chỉemail:ntnthuy@hcmute.edu.vn

https://doi.org/10.25073/2588-1159/vnuer.4368
}

mối cho những hoạt động công tác xã hội được triển khai và đạt được nhiều đánh giá tích cực.

\section{Quản trị công tác xã hội và triết lý giáo dục của nhà trường}

\section{1. Định nghĩa}

Năm 1950, Kidneigh cho rằng quản trị công tác xã hội là một tiến trình chuyển đổi chính sách xã hội thành các dịch vụ xã hội,... trong một tiến trình hai chiều: (1) ... chuyển đổi chính sách thành các dịch vụ xã hội cụ thể, và (2) sử dụng kinh nghiệm để sửa đổi điều chỉnh chính sách. Spencer cho rằng có sự nhất trí chung cho rằng: "Quản trị là sự lãnh đạo có ý thức những hoạt động và quan hệ nội bộ của doanh nghiệp để đạt được những mục đích đề ra". Bà cũng thêm rằng nó bao gồm "sự can 
thiệp có ý thức vào các lực tương tương tác giữa cơ sở và cộng đồng rộng lớn hơn mà nó là một bộ phận". Duham mô tả quản trị như là tiến trình "hỗ trợ hoặc tạo thuận lợi những hoạt động cần thiết và thử yêu đối với việc cung cấp trực tiếp dịch vụ của một cơ sở xã hội” [1]. Hoạt động quản trị bao gồm từ xác định chức năng và chính sách, lãnh đạo điều hành các hoạt động tác nghiệp thông thường như lưu giữ hồ sơ và kế toán và trong nông sản dịch vụ bảo dưỡng. Stein cho rằng định nghĩa về quản trị thì nhiều, nhưng tựu chung được chấp nhận hay hiện nay là quan niệm coi "Quản trị là một tiến trình xác định và đạt tới những mục tiêu của một tổ chức thông qua một hệ thống phối hợp và hợp tác các nỗ lực". Trecker diễn dịch: quản trị công tác xã hội là "một tiến trình làm việc với con người bằng cách phát huy và liên kết năng lực của họ để họ sử dụng mọi tài nguyên sẵn có để thực hiện mục đích cung cấp cho cộng đồng những chương trình và dịch vụ cần đến" [1]. Quản trị công tác xã hội đang đến tuổi trưởng thành. Những người lãnh đạo giỏi cơ sở xã hội ngày càng là những nhà quản trị công tác xã hội chứ không phải là những nhà quản trị có kiến thức ngành công tác xã hội. Nhiều nhà điều hành cơ sở và giám sát viên (kiểm huấn viên) đã qua huấn luyện ở các trường công tác xã hội cho vị trí mà họ đảm nhiệm. Ngành Quản trị "như là một lĩnh vực trong công tác xã hội có được một chỗ đứng đúng đắn, và quản trị công tác xã hội là một phương pháp thực hành công tác xã hội căn bản giống như công tác xã hội cá nhân hay công tác xã hội nhóm đã có từ trước" [1].

\subsection{Triết lý giáo dục của nhà trường}

"Nhân bản, sáng tạo, hội nhập" là triết lý của nhà trường với ý nghĩa chung là: Cộng đồng các nhà quản lí, giảng viên, sinh viên và các bên liên quan của Trường Đại học Sư phạm Kỹ thuật thành phố Hồ Chí Minh cùng tham gia vào quá trình giáo dục, truyền cảm hứng và trợ giúp từng sinh viên trở thành các cá nhân có năng lực, lương tâm và trách nhiệm; khắc sâu trong tâm trí sinh viên tầm quan trọng của các kĩ năng mới, các kĩ năng của công dân toàn cầu, các kĩ năng khởi nghiệp và những kĩ năng cốt lõi khác.

Trường Đại học Sư phạm Kỹ thuật thành phố Hồ Chí Minh tin rằng việc học có ý nghĩa đầy đủ nhất khi từng cá nhân được tạo các cơ hội cho sự phát triển toàn diện các năng lực về nhận thức; xã hội; hành vi và chuyên môn kĩ thuât. Trường Đai học Sư phạm Kỹ thuật thành phố Hồ Chí Minh cũng tin vào những giá trị cốt lõi của học tập suốt đời: từng cá nhân người học cần tự kiến tạo và mở rộng kiến thức, kĩ năng của chính bản thân để phát huy tiềm năng sáng tạo, qua đó thực hiện nguyện vọng của bản thân và phụng sự xã hội.

Các giá trị cơ bản của một nền giáo dục tiên tiến; hiện đại đã, đang và sẽ được Trường Đại học Sư phạm Kỹ thuật thành phố Hồ Chí Minh tôn vinh, gìn giữ, phát huy một cách sáng tạo là: (1) Giữ gìn và phát huy các giá trị truyền thống nhân văn của dân tộc Việt Nam; (2) Nâng đỡ tài năng và tính sáng tạo; chú trọng đào tạo kỹ năng và trách nhiệm nghề nghiệp; (3) Tôn trọng lợi ích của người học và của cộng đồng. Xây dựng xã hội học tập; (4) Đề cao chất lượng, hiệu quả và sự đổi mới trong các hoạt động; (5) Hội nhập, hợp tác và chia sẻ $[2$, Trường Đại học Sư phạm Kỹ thuật thành phố Hồ Chí Minh: Triết lý giáo dục].

\section{Thực trạng quản trị công tác xã hội theo triết lý giáo dục tại Trường Đại học Sư phạm Kỹ thuật thành phố Hồ Chí Minh}

Quy chế học sinh, sinh viên các trường đại học, cao đẳng và trung cấp chuyên nghiệp hệ chính quy ban hành kèm theo Quyết định số 42/2007/QĐ-BGDĐT ngày 13/8/2007 của Bộ trưởng Bộ Giáo dục và Đào tạo đã được thay thế bằng Thông tư 10/2016/TT-BGDĐT ngày 05/4/2016 của Bộ trưởng Bộ Giáo dục \& Đào tạo về việc ban hành Quy chế công tác sinh viên đối với chương trình đào tạo Đại học hệ chính quy quy định rõ tại Khoản 7 , Điều 4 về nghĩa vụ của sinh viên: "Tham gia lao động công ích, hoạt động tình nguyện, hoạt động xã hội vì cộng đồng phù hợp với năng lực và sức khỏe theo yêu cầu của cơ sở giáo dục đại học". Căn cứ vào quyết định của $B$ ộ trưởng Bộ giáo dục 
và Đào tạo, Hiệu trưởng Trường Đại học Su phạm Kỹ thuật thành phố Hồ Chí Minh ban hành Quy định thực hiện chương trình Công tác xã hội đối với SV hệ chính quy theo Quyết định số 224/QĐ-ĐHSPKT-CTHSSV ngày 09/12/2013 với mục đích phát huy tinh thần xung kích, tình nguyện của sinh viên vì cộng đồng; nhân ái, tương trợ và chủ động góp sức trẻ tham gia giải quyết các vấn đề đang được nhà trường và xã hội quan tâm, là những nền tảng dựa vào đó những dịch vụ được triển khai và sẵn sàng cho những ai cần đến chúng [3]. Qua đó nâng cao ý thức trách nhiệm của sinh viên đối với bản thân và cộng đồng; rèn luyện, nâng cao tính chủ động, sáng tạo, linh hoạt trong hoạt động thực tiễn; hình thành các kỹ năng sống, trau dồi bản lĩnh tổ chức công việc, ... cho sinh viên trước khi ra trường. Sau khi Quy định được ban hành, các đơn vị và sinh viên toàn trường hưởng ứng và thực hiện nghiêm túc.

Năm học 2013 - 2014 là năm đầu tiên triển khai thực hiện Quy định, nhà trường chỉ đạo và triển khai hoạt động qua việc xây dựng phần mềm quản lý hoạt động công tác xã hội; tập huấn cán bộ thực hiện các nội dung liên quan đến chương trình công tác xã hội; ban hành hướng dẫn sử dụng phần mềm quản lý hoạt động công tác xã hội, hướng dẫn giải quyết khiếu nại, các văn bản biểu mẫu đính kèm theo quy trình thực hiện hoạt động,... Ngày 06/3/2014, lãnh đạo nhà trường cùng các đơn vị có liên quan đã tiến hành họp đánh giá 01 năm thực hiện quy định ngày công tác xã hội đối với sinh viên hệ chính quy từ khóa 2012.

Đầu mỗi năm học, Hiệu trưởng ban hành các Kế hoạch chỉ đạo các đơn vị và sinh viên thực hiện triển khai chương trình: Năm học 2014 - 2015, theo Kế hoạch số 430/KHĐHSPKT-CTHSSV ngày 01/10/2014; Năm học 2015 - 2016, theo Kế hoạch số 230/KHĐHSPKT-CTHSSV ngày 10/10/2015; Năm học 2016 - 2017, theo Kế hoạch số 237/KHĐHSPKT-CTHSSV ngày 17/10/2016; Năm học 2017 - 2018, theo Kế hoạch số 295/KHĐHSPKT-CTHSSV ngày 28/11/2017; Năm học 2018 - 2019, theo Kế hoạch số $318 / \mathrm{KH}-$ ĐHSPKT-CTHSSV ngày 23/10/2018. Kết thúc mỗi năm học, chương trình công tác xã hội được báo cáo, thống kê, nhận định qua các Báo cáo số 27/BC-ĐHSPKT-CTHSSV ngày 05/3/2015, số 20/BC-ĐHSPKT-CTHSSV ngày 11/4/2016, số 64/BC-ĐHSPKT-TS\&CTSV ngày $18 / 11 / 2017$, số $68 \mathrm{a} / \mathrm{BC}$-ĐHSPKTCTHSSV ngày 30/7/2018 [4].

Bằng triển khai chặt chẽ và định hướng từng năm học qua các văn bản ban hành, các đơn vị đã thường xuyên tuyên truyền, tổ chức các hoạt động công tác xã hội cho sinh viên tham gia, sơ kết, rút kinh nghiệm và luôn cải tiến, đổi mới trong hoạt động nhằm thực hiện tốt Quy định. Theo đó, các hoạt động công tác xã hội trong trường học được triển khai đều cho mỗi học kỳ, xem Hình 3.1.

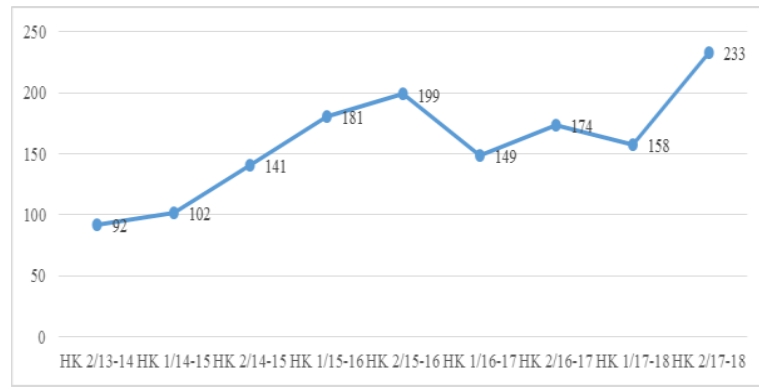

Hình 3.1. Số hoạt động công tác xã hội theo từng học kỳ.

Nguồn: Thống kê của phòng công tác học sinh sinh viên của nhà trường

Nhìn vào biểu đồ cho thấy rằng, các hoạt động công tác xã hội theo từng học kỳ có sự biến động khá đa dạng, cụ thể, từ học kỳ $1 / 13$ 14 đến học kỳ 2/15-16 có dự gia tăng không ngừng về các hoạt động công tác xã hội phục vụ cộng đồng; nhưng từ học kỳ 2/15-16 đến học kỳ 1/16-17, các hoạt động công tác xã hội phục vụ cộng đồng có vẻ giảm đi. Tuy nhiên, đến các học kỳ tiếp theo, nhà trường đã triển khai nhiều hoạt động công tác xã hội phục vụ cộng đồng trở lại, đặc biệt, chỉ tính từ học kỳ 1/17-18 đến học kỳ 2/17-18 đã tăng lên 75 hoạt động công tác xã hội. Điều này cho thấy rõ ràng giá trị "Giữ gìn và phát huy các giá trị truyền thống nhân văn của dân tộc Việt Nam" và "Tôn trọng lợi ích của người học và của cộng đồng" trong triết lý giáo dục của nhà trường được phát huy một cách hiệu quả. 
Các hoạt động công tác xã hội được triển khai và tổ chức được khá đa dạng và phong phú, hướng đến các nhóm cộng đồng như là sinh viên, các nhóm "yếu thế" trong xã hội dưới sự hỗ trợ của Nhà trường và các đơn vị trong trường, xem Bảng 3.1.

Có thể dễ dàng nhận thấy rằng, các hoạt động công tác xã hội mà sinh viên lựa chọn nhiều nhất là chủ nhật xanh, sắp xếp kho/xưởng/phòng học của khoa; hỗ trợ các khoa/phòng ban/thư viện các hoạt động của đơn vị; tiếp đến là các hoạt động phong trào gắn liền với môi trường học tập của sinh viên (chiếm tỷ lệ lần lượt là $19.9 \%, 14.9 \%$ và 13.6\%). Một số các hoạt động khác phục vụ cộng đồng như hiến máu tình nguyện; mùa hè xanh/tiếp sức mùa thi, xuân tình nguyện, trung thu,... cũng được sinh viên tham gia khá nhiều (chiếm tỷ lệ lần lượt là $12.8 \%$ và $14.5 \%$ ).

Những nhu cầu của cộng đồng và cá nhân trong cộng đồng ấy luôn luôn là nền tảng cơ bản cho sự tồn tại của cơ sở xã hội và sự cung ứng các chương trình. Theo số liệu thống kê của nhà trường, các đơn vị thường xuyên tổ chức các hoạt động, trung bình mỗi học kỳ có 159 hoạt động, 11,674 sinh viên tham gia các hoạt động và thu về 108,404 điểm công tác xã hội; nếu chỉ tính tính riêng 03 năm học gần đây (từ 2015-2016 đến 2017-2018) thì số lượng này cụ thể mỗi học kỳ có 182 hoạt động, 12,287 sinh viên tham gia các hoạt động và thu về 110,957 điểm công tác xã hội [4], xem Hình 3.2.

Để hoạt động quản trị công tác xã hội có hiệu quả, nhà trường phải được hiểu trong tính toàn bộ và tính nguyên bản của nó. "Nó phải được xem như là một công cụ sáng tạo nên bởi các bộ phận có liên quan với nhau" [5]. Ngay từ khi Hiệu trưởng ban hành Quyết định thực hiện Quy định chương trình công tác xã hội đối với sinh viên hệ chính quy, Nhà trường đã đặt hàng công ty $\mathrm{PSC}$ xây dựng và đưa vào sử dụng phần mềm quản lý hoạt động công tác xã hội. Đến nay, phần mềm vẫn được sử dụng hiệu quả và hoàn thành tốt các yêu cầu từ nhà trường. Phần mềm có các chức năng sau: (1) Lập kể hoạch hoạt động công tác xã hội, hiển thị đầy đủ thông tin chi tiểt về hoạt động, đơn vị tổ chức, các yêu cầu từ đơn vị tổ chức lên trang online sinh viên; (2) Cho sinh viên đăng ký tham gia hoạt động trên trang online sinh viên, có chức năng giới hạn sinh viên tham gia theo yêu cầu của đơn vị tổ chức; (3) Nhập điểm công tác xã hội cho sinh viên sau khi sinh viên hoàn thành chương trình công tác xã hội; (4) Hiển thị điểm công tác xã hội của sinh viên liên trang online để sinh viên theo dõi; (5) Xuất các biểu mẫu, bảng điểm cho sinh viên khi sinh viên cần; (5) Thống kê số liệu sinh tham gia hoạt động,...

Bảng 3.1. Hoạt động công tác xã hội được sinh viên tham gia

\begin{tabular}{llll}
\hline Nội dung & Các phương án trả lời & $\begin{array}{l}\text { Số lượt } \\
\text { chọn }\end{array}$ & $\begin{array}{l}\text { Tỉ lệ } \\
(\%)\end{array}$ \\
\hline & Tham gia Mùa hè xanh, Tiếp sức mùa thi, Xuân tình nguyện, Trung thu & 852 & 14.5 \\
$\begin{array}{l}\text { Anh/Chị } \\
\text { thường }\end{array}$ & Tham gia Hiến máu tình nguyện & 751 & 12.8 \\
$\begin{array}{l}\text { xuyên } \\
\text { tham gia }\end{array}$ & Tham gia hoạt động tư vấn hướng nghiệp, tuyển sinh & 483 & 8.2 \\
hoạt động & Hỗ trợ các Khoa/Phòng/Trung tâm/Thư viện các hoạt động của các đơn vị & 875 & 14.9 \\
$\begin{array}{l}\text { CTXH nào } \\
\text { sau đây (có } \\
\text { thể chọn }\end{array}$ & Hoạt động Chủ nhật xanh, sắp xếp kho/xưởng/phòng học của khoa & 1.171 & 19.9 \\
$\begin{array}{l}\text { nhiều } \\
\text { câu)? }\end{array}$ & Tham gia các hoạt động chăm lo cho người già neo đơn, trẻ em & 248 & 4.2 \\
& Tham gia giảng dạy chuyên môn, trợ giảng & 135 & 2.3 \\
\hline
\end{tabular}

Nguồn: Thống kê của phòng công tác học sinh sinh viên của nhà trường 


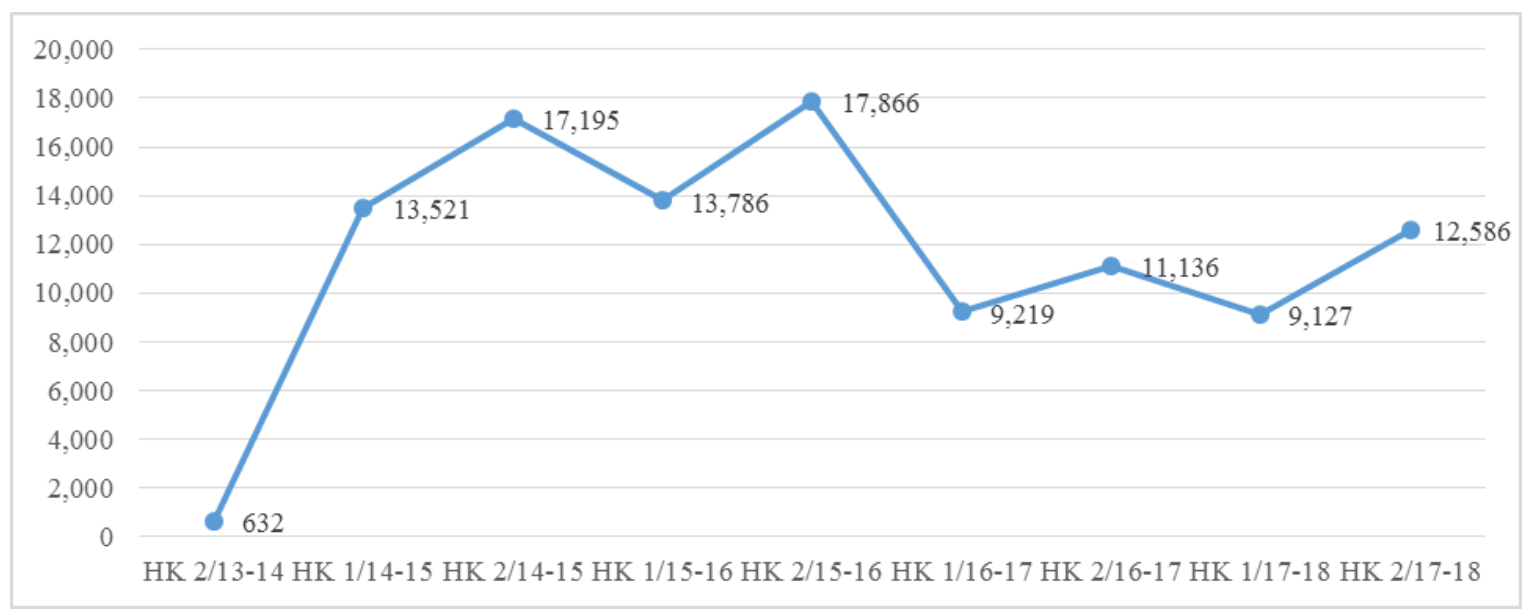

Hình 3.2. Số lượng sinh viên tham gia công tác xã hội theo từng học kỳ.

Nguồn: Thống kê của phòng công tác học sinh sinh viên của nhà trường.

Qua quá trình sử dụng, phần mềm được điều chỉnh các quy trình thực hiện sao cho phù hợp với thực tế của các đơn vị trong trường, đảm bảo khai thác tốt và hướng đển nhanh chóng, công khai, minh bạch. Và hiện tại có 19 đơn vị trong nhà trường đã được cấp tài khoản và sử dụng phần mềm để thực hiện các quy trình tổ chức các hoạt động công tác xã hội.

Trường Đại học Sư phạm Kỹ thuật thành phố Hồ Chí Minh đã và đang đưa vào triển khai chương trình đào tạo 132 tín chỉ với nhiều cải tiến trong đào tạo cũng như phương pháp giảng dạy, kiểm tra, đánh giá; phát huy tối đa năng lực của người học; hướng người học đến với xã hội, phục vụ cộng đồng, xây dựng đất nước. Bên cạnh đó, Trường Đại học Sư phạm Kỹ thuật thành phố Hồ Chí Minh thực hiện thí điểm đổi mới cơ chế hoạt động lộ trình tự chủ tài chính; các ngành đào tạo tại trường tiến đến kiểm định chất lượng quốc tế AUN-QA, $\mathrm{ABET}, \ldots$ đây cũng là yếu tố cần sinh viên trường phải nỗ lực tham gia hoạt động cộng đồng, xây dựng hình ảnh tốt đẹp của Trường Đại học Sư phạm Kỹ thuật thành phố Hồ Chí Minh với xã hội. Sinh viên Trường Đại học Sư phạm Kỹ thuật thành phố Hồ Chí Minh ngày càng năng động, sáng tạo và chủ động hội nhập, tình nguyện vì cộng đồng [4].

Thực hiện triết lý nhân bản, sáng tạo, hội nhập, việc giữ gìn và phát huy các giá trị truyền thống nhân văn của dân tộc Việt Nam; chăm lo đời sống, đáp ứng nhu cầu và nguyện vọng cho nhóm cộng đồng đông đảo trong nhà trường đó chính là sinh viên. "Góc chia sé" được hình thành để đón nhận tấm lòng hảo tâm từ các tổ chức, cá nhân, doanh nghiệp bên ngoài cũng như các cán bộ, sinh viên trong nhà trường. PGS.TS Đỗ Văn Dũng, hiệu trưởng nhà trường, cho biết để thể hiện triết lý giáo dục "nhân bản sáng tạo - hội nhập", đặt giá trị nhân văn lên hàng đầu, nhà trường sẽ tồ chức nhiều hoạt động, công trình chăm lo sâu sắc đời sống vật chất, tinh thần cho sinh viên. Khu nghỉ trưa máy lạnh hoạt động từ $11 \mathrm{~h}-13 \mathrm{~h}$, từ thứ hai đến thứ sáu. Sinh viên được ra vào khu vực này tự do. "Thực tế tôi chứng kiến nhiều sinh viên rất mệt mỏi, ngủ gục khắp nơi trong trường mỗi giờ trưa chờ để học tiếp vào buổi chiều trông rất tội nghiệp. Chúng tôi nghĩ ngay đến việc tận dụng khu vực hội trường bố trí chỗ nghỉ trưa đàng hoàng hơn cho sinh viên. Sau khi phát động, nhà trường nhận được quyên tặng bởi các cựu sinh viên, thầy cô giáo, nhà hảo tâm 120 chiếc võng để đưa vào khu nghỉ trưa này; nhà trường đã bố trí 60 - 70 võng vào nằm nghỉ trưa (Hiệu trưởng Trường Đại học Sư phạm Kỹ thuật chia sẻ).

Cũng nằm trong chuỗi hoạt động ấy, "Góc sẻ chia" trở thành nơi đón nhận và lan tỏa những tấm lòng cao đẹp đồng hành, hỗ trợ, giúp đỡ sinh viên có hoàn cảnh kém may mắn. Cho đến nay, Góc chia sẻ đã hỗ trợ các em một cách thiết thực, bền vững, phải tạo ra một không gian 
để giúp đỡ các em hàng ngày, hàng giờ. Đó là những chiếc xe đạp, đồ dùng học tập, sách vở, gạo, thùng mì gói,... Tất cả là tấm lòng của các mạnh thường quân, các thành viên trong trường góp sức.

Như đã thống kê ở trên, các hoạt động chăm lo cho người già neo đơn, trẻ em do Đoàn, Hội sinh viên cũng như trung tâm dịch vụ sinh viên phối hợp tổ chức đã đển được với các nhóm cộng đồng yếu thế trong xã hội. Những hoạt động từ thiện, Trung thu yêu thương, Tết sẻ chia,... đã góp phần kết nối được những hoạt động vì cộng đồng của sinh viên, và các đơn vị trong trường.

\section{Những vấn đề đặt ra}

Theo nhận định trong dự thảo báo cáo đánh giá 5 năm thực hiện công tác xã hội của nhà trường thì nhân sự phụ trách công tác tổ chức các hoạt động công tác xã hội tại các khoa ít, thường được gắn với Bí thư Đoàn khoa (là cán bộ viên chức) kiêm nhiệm phụ trách, không có nhiều thời gian đầu tư cho hoạt động.

Hơn nữa, vì có quá nhiều đơn vị tổ chức các hoạt động công tác xã hội trong nhà trường: Trung tâm dịch vụ sinh viên, Đoàn - Hội sinh viên, các Khoa, phòng ban nên nhiều khi các hoạt động và chức năng chồng chéo lên nhau. Nên thiết nghĩ, căn cứ trên mục tiêu chất lượng cũng triết lý giáo dục của nhà trường trong xu thế hội nhập, nhà trường cần có Trung tâm công tác xã hội hoặc mở ngành đào tạo Công tác xã hội (vừa đào tạo nhân viên công tác xã hội để cung cấp nguồn lực cho xã hội, vừa tổ chức và thực hành công tác xã hội, trang bị các phương pháp công tác xã hội một cách đồng bộ, trong đó quản trị ngành) để mang lại tính hiệu quả cao hơn.

Như đã phân tích ở trên, những người lãnh đạo giỏi cơ sở xã hội ngày càng là những nhà quản trị công tác xã hội chứ không phải là những nhà quản trị có kiến thức ngành công tác xã hội,... [3]. Và quản trị công tác xã hội là một phương pháp thực hành công tác xã hội căn bản giống như công tác xã hội cá nhân hay công tác xã hội nhóm đã có từ trước [5]. Mặc dầu đã đạt được những kết quả nhất định trong các hoạt động vì cộng đồng, nhưng đặc thù là một trường đào tạo về kỹ thuật, nên khi nói đến các hoạt động công tác xã hội tại trường, người ta thường nghĩ đến những hoạt động công tác xã hội trong sinh viên, những hoạt động thiện nguyện, ít khi nhắc đến vai trò của quản trị công tác xã hội trong nhà trường.

Các đơn vị ngoài trường ghi nhận kết quả tham gia các hoạt động công tác xã hội của sinh viên là một tiêu chí đánh giá để xét tuyển dụng, xét học bổng, xét các danh hiệu sinh viên, điều đó thể hiện việc sinh viên tham gia các hoạt động công tác xã hội là điều mà các đơn vị, doanh nghiệm và xã hội cần và khuyến khích. Rõ ràng là các doanh nghiệp đang có xu hướng hướng đến các hoạt động công tác xã hội trong trường học, nhưng họ chỉ dừng lại ở việc ghi nhận kết quả chứ chưa cho thấy vai trò kết nối của các doanh nghiệp với các hoạt động công tác xã hội trong sinh viên.

Một bộ phận nhỏ sinh viên trường vẫn còn bàn quan, chưa ý thức được trách nhiệm của sinh viên là phải tham gia hoạt động xã hội; chủ quan, không thực hiện nghiêm túc quy định.

Việc tổng kết đánh giá kết quả hoạt động công tác xã hội 5 năm một lần trong trường học có vẻ chưa thực sự hợp lý, bởi nhà quản trị cần nắm được khả năng hỗ trợ cũng như mức độ đáp ứng nhu cầu, mong đợi của các nhóm đối tượng kịp thời nhằm có những hoạt động hỗ trợ hợp lý trong từng giai đoạn khác nhau.

\section{Kết luận}

Tuy vẫn còn những tồn tại, hạn chế nhất định trong việc tổ chức và thực hiện các hoạt động công tác xã hội, nhưng với triết lý giáo dục "nhân bản, sáng tạo, hội nhập" trong quá trình hội nhập và sáng tạo, quản trị công tác xã hội tại Trường Đại học Sư phạm Kỹ thuật thành phố Hồ Chí Minh - với nguyên tắc quản lý, tính hiệu quả và tính kết quả đã được vận dụng một cách thiết thực dựa trên các mối quan hệ nhân sự đã và đang có trong nhà trường, chính vì vậy trong lĩnh vực quản trị các cơ sở dịch vụ xã hội (như trung tâm dịch vụ sinh viên, Đoàn - hội 
sinh viên, các Khoa chuyên ngành) đã góp phần giúp họ đảm nhận tốt chức năng nhà quản lý, tổ chức cơ sở và người cán sự xã hội tận tụy với công việc giúp đỡ con người.

Các hoạt động công tác xã hội trong trường học được triển khai và đáp ứng nhu cầu của cộng đồng sinh viên trong nhà trường; nhiều hoạt động hướng đến và hỗ trợ, giúp đỡ các nhóm cộng đồng yếu thế như chiến dịch xuân tình nguyện, mùa hè xanh, hiến máu nhân đạo,... đã khuyến khích được đông đảo sinh viên trong nhà trường tham gia, góp phần cụ thể hóa ý nghĩa của "việc học có ý nghĩa đầy đủ nhất khi từng cá nhân được tạo các cơ hội cho sự phát triển toàn diện các năng lực về nhận thức; xã hội; hành vi và chuyên môn kĩ thuật". Các hoạt động này ít nhiều đã phản ánh được tinh thần và trách nhiệm vì một cộng đồng đoàn kết, một xã hội văn minh, phát triển và thịnh vượng, vì những con người yếu thế đang cần đến sự hỗ trợ của các "thân chủ" mà cộng đồng Trường Đại học Sư phạm Kỹ thuật thành phố Hồ Chí Minh đang triển khai theo triết lý lý giáo dục nhân bản của nhà trường.

Hoạt động đánh giá, kiểm huấn quản trị công tác xã hội trong trường học được triển khai theo lộ trình nhằm không ngừng nâng cao hiệu quả hoạt động cộng đồng trong sinh viên trong giai đoạn mới, nhận định những mặt đạt được, cần phát huy và những vướng mắc cần được điều chỉnh, sửa đổi cho phù hợp với thực tế tại trường, từ đó xây dựng mới quy định về hoạt động công tác xã hội.

\section{Tài liệu tham khảo}

[1] Le Chi An, Governance of social work, Thanh Hoa Publishing House, 2007. (in Vietnamese).

[2] Ho Chi Minh City University of Technology and Education, Philosophy of Education: https://hcmute.edu.vn/triet-ly-giao-duc/, 2019 (accessed 28 November 2019). (in Vietnamese).

[3] Announcement No. 317 / TB-DHSPKT, October 23, 2018, On the implementation of 5-year assessment of the implementation of social work program for regular students, 2018. (in Vietnamese).

[4] Draft Report summarizing 05 years of implementing regulations on organizing social work programs of regular students (20132018)/BC-DHSPKT-TS \& CTSV/November, 2018. (in Vietnamese).

[5] A. Harry Schatz, Tran Quy Hung (translated), Social work administration, Social bookcase published before, 1975. (in Vietnamese). 